\title{
LA TUTELA JURISDICCIONAL DE LOS DERECHOS FUNDAMENTALES: UNA PROPUESTA EN CLAVE DEMOCRÁTICA*
}

\section{THE JUDICIAL PROTECTION OF FUNDAMENTAL RIGHTS: A DEMOCRATIC PROPOSAL}

\author{
Felipe Ignacio Paredes Paredes ${ }^{1}$
}

\begin{abstract}
RESUMEN: Una cuestión de crucial importancia para el Estado Constitucional de Derecho es la tutela jurisdiccional de los derechos fundamentales. A pesar de esto, he escrito poco sobre el tema. Lo que se propone en el siguiente artículo es que la idea de garantía jurisdiccional no solo es determinante para la efectividad de los derechos fundamentales, sino que también que a través de la praxis jurisdiccional se le va dando forma y contenido a los mismos. Es por ello que se debe poner especial cuidado en su diseño institucional de modo, que el proceso de adjudicación constitucional sea lo menos lesivo con el principio democrático. Ello no es baladí, pues esta es es la otra fuente de legitimidad a la que recurren las Constituciones contemporáneas.
\end{abstract}

Palabras clave: Derechos fundamentales, democracia, garantía jurisdiccional, constitucionalismo.

ABSTRACT: A matter of crucial importance to the constitutional rule of law is the judicial protection of fundamental rights. Despite this, the literature has not written much on the subject. What is proposed in the following paper is that the idea of judicial guarantee is not only crucial to the effectiveness of fundamental rights, but also that through the judicial praxis is going to give form and content thereof. Therefore, you should take special care in its institutional design so that the process of constitutional adjudication is least harmful to the democratic principle. This is not trivial, as this is the other source of legitimacy resorting to contemporary constitutions.

Key words: Fundamental rights, democracy, judicial protection, constitutionalism.

\section{INTRODUCCIÓN}

El presente trabajo articula una serie de reflexiones, que buscan hacer frente al desafío que representa para la democracia la tutela jurisdiccional de los derechos fundamentales. A pesar de que las declaraciones de derechos son un lugar común en las Constituciones de nuestros días, el constitucionalismo, tal como lo entendemos, representa una paradoja, al fundarse sobre dos principios en apariencia contradictorios: por una parte el principio de autodeterminación de los ciudadanos, que exige que estos decidan por sí mismos todo

\footnotetext{
* Este trabajo forma parte del proyecto FONDECYT N 1130076 "Límites al Ius Puniendi y Derechos Fundamentales: Bases para una dogmática integrada en el control de constitucionalidad”, del cual el autor es coinvestigador".

1 Abogado, Doctor de Derecho, Profesor de Derecho Constitucional de la Universidad Austral de Chile, Independencia 641, Valdivia, Chile. Felipe.paredes@uach.cl
} 
aquello que concierne a su libertad, y por otra, los derechos fundamentales que imponen limitaciones al ejercicio del poder sustrayendo de la esfera de lo decidible una serie de materias que se consideran indisponibles para la política ${ }^{2}$. Esta circunstancia ha dado lugar a un prolífico debate filosófico, que entre nosotros comienza a adquirir relevancia.

Sin perjuicio de lo anterior, este es un trabajo de teoría constitucional y no de filosofía política. En dicha calidad, no busca contestar la pregunta acerca de la relevancia de la dificultad contramayoritaria. Más bien la asume como un hecho de la causa, teniendo en cuenta de que tanto la democracia como la protección de los derechos fundamentales forman parte del sistema constitucional chileno, de modo que ninguno de estos dos principios puede ser soslayado en nuestro análisis, debiéndose buscar la manera de optimizarlos y hacerlos convivir de la manera más armónica posible. En este sentido, partimos de una doble opción política: el compromiso con la democracia y la asunción de que los derechos fundamentales cumplen un importante papel en la configuración de sociedad ordenada sobre la base del ideal normativo del Estado de Derecho.

Esto supone una premisa: la tensión entre democracia y derechos es inevitable. La razón está dada por la misma naturaleza de los derechos fundamentales, que se consagran a través de normas con un contenido indeterminado, muchas veces ambiguas, y que al mismo tiempo, se sitúan en un sitial de privilegio dentro del sistema de fuentes. Si nos tomamos esto en serio, tendremos como consecuencia a jueces dotados con capacidad para desafiar al legislador, quien como sabemos, expresa institucionalmente la democracia representativa. En este sentido, estas líneas deben entenderse como un intento por discutir los cimientos de una teoría de los derechos fundamentales respetuosa por los modos de adopción de decisiones intersubjetivas propias de una democracia, que además pueda servir de utilidad para el ordenamiento jurídico chileno. Como la empresa es novedosa, las referencias a la literatura comparada serán frecuentes.

Antes que todo, una aclaración debe ser hecha: en esta oportunidad, trataremos a la democracia como una categoría abstracta, y por tanto, nada diremos acerca del modelo de democracia vigente en el sistema constitucional chileno. Por esta razón, nuestro análisis será del tipo ceteris paribus, es decir, nuestra concepción trata de elaborar una noción de derechos fundamentales que fuera capaz de interactuar frente al mejor concepto de democracia posible.

En síntesis, la propuesta descansa sobre la siguiente hipótesis: la idea de garantía jurisdiccional es altamente incidente en el contenido de los derechos fundamentales, y en este sentido, es tan importante que lo que se denomina el contenido preceptivo u "objetivo" de los derechos ${ }^{3}$. Intentaremos justificar dicha hipótesis sobre la base del siguiente esquema: comenzaremos explicando someramente el concepto y el rol de la garantía jurisdiccional en la teoría de los derechos fundamentales (II); acto seguido nos centraremos en la dificultad que ha tenido la doctrina para abordar una noción de contenido objetivo de los derechos fundamentales y de encuadrar el proceso de adjudicación constitucional como una actividad netamente jurídica, (III); en tercer lugar discutiremos el papel que juegan en una socie-

\footnotetext{
2 Habermas y Regh (2001) pp. 766-767.

3 Pérez Luño (2007) p. 20.
} 
dad democrática los consensos y los desacuerdos como un elemento clave a la hora de fijar una regla de competencia que permita gestionar aquellos bienes jurídicos que consideramos de vital importancia en nuestra sociedad (IV); finalmente, la conjugación de todos estos elementos nos debería permitir poder articular una respuesta a la interrogante de cuál es (o debe ser) el papel de la judicatura en la tutela de los derechos fundamentales y bajo qué condiciones esta debería ser proporcionada.

\section{LA GARANTÍA DE LOS DERECHOS FUNDAMENTALES}

La principal característica de los derechos fundamentales en las Constituciones contemporáneas es su garantía jurisdiccional ${ }^{4}$. Esta circunstancia representa un verdadero desafío para el diseño institucional, pues si asumimos que los derechos fundamentales son límites para todos los poderes del Estado, deberíamos saber con certeza cuál es su contenido.

Partiendo de la base de que tutela jurisdiccional es aquella proporcionada a través del ejercicio de la actividad jurisdiccional ${ }^{5}$, la doctrina comparada, en el afán por entender cabalmente este fenómeno jurídico, ha realizado al respecto una completa taxonomía ${ }^{6}$. De esta manera, los distintos procedimientos de garantía jurisdiccional se pueden agrupar dentro de dos grandes especies: los mecanismos de carácter subjetivo y los de carácter objetivo 7 . Grosso modo, los primeros dicen relación con concebir a los derechos fundamentales como derechos subjetivos, los segundos no son sino la consecuencia lógica que se deriva de la síntesis de dos ideas: la primera, la especial posición que ocupa los derechos fundamentales dentro del sistema de fuentes, y la segunda, la existencia de Constituciones con valor normativo directo.

\section{LA GARANTÍ́A SUBJETIVA DE LOS DERECHOS FUNDAMENTALES}

Las garantías subjetivas dicen relación con todos aquellos mecanismos que tienen por finalidad reparar una vulneración concreta de un derecho que ha sufrido un particular. En definitiva, lo que se busca es la protección de derechos e individuos concretos frente a actuaciones de los poderes públicos restableciendo el derecho vulnerado. Como señala Garrido $^{8}$, en este caso "la garantía se activa por sujetos de derecho que inician para su defensa un proceso jurisdiccional en el que se decide sobre derechos e intereses específicos”. La idea es bastante simple: si a una persona el Estado le vulnera uno de esos derechos denominados fundamentales, este último incurre en responsabilidad para con esa persona.

\footnotetext{
4 Cruz Villalón (1989) p. 79.

5 La noción de jurisdicción aquí utilizada es más amplia que el concepto técnico que se emplea en el Derecho procesal chileno, e incluye a cualquier tribunal que aplica la Constitución como criterio para la resolución de conflictos en el marco de un proceso. En este sentido, comprende tanto a un Tribunal constitucional como el chileno que se encuentra fuera del Poder Judicial, como al resto de Tribunales especiales que puedan resultar competentes para ejercer esta atribución, ya sea dentro o fuera de dicho poder del Estado.

6 Fernández Segado (1997) p. 472.

7 López Guerra (2004) pp. 337-245.

8 GARRIDO (2007) p. 166.
} 
Desde esta perspectiva, existe una larga tradición de pensamiento que vincula los derechos fundamentales a las formas de razonamiento y aplicación típicas del Derecho privado. Sin embargo, se suele olvidar por los iuspublicistas que la afirmación de que los derechos fundamentales son estructuralmente derechos subjetivos debe ser tomada con beneficio de inventario, pues ellos no pueden ser derechos subjetivos en el mismo sentido de los derechos subjetivos privados, debido a que existen diferencias importantes entre unos y otros en cuanto a las características de los enunciados lingüísticos propios de cada categoría. Ya diremos algo sobre esto. En general, en teoría del derecho existe cierto consenso en relación a qué es lo que significa en la práctica ser titular de un derecho subjetivo. Esta cuestión ha quedado más o menos clara, a partir de los estudios de Wesley N. Hohfeld ${ }^{9}$, y hoy es generalmente aceptado que los derechos subjetivos confieren a su titular situaciones jurídicas favorables que son susceptibles de ser invocadas jurisdiccionalmente ante los tribunales. En síntesis, en el análisis de Hohfeld se habla de que un derecho subjetivo puede dar lugar a cuatro tipos de relaciones entre los sujetos involucrados en la relación jurídica: right (derecho), duty (deber), no-right (no derecho), Power (competencia). En otras palabras, un derecho subjetivo consiste en una determinada facultad para conseguir que alguien realice o no realice de manera compulsiva un determinado comportamiento. Como sabemos, esta es la misma idea que los tribunales tienen acerca de la manera como funcionan los derechos fundamentales, con la particularidad de que en este último caso el obligado será siempre el Estado. En otras palabras, un derecho fundamental permite a su titular conseguir que el Estado se abstenga de realizar una determinada acción o realice una prestación a favor de una persona ${ }^{10}$.

Pero bien, decíamos que los derechos fundamentales difieren en gran medida de los derechos subjetivos sin más, pues en ellos no siempre es sencillo conocer de la sola lectura de la norma constitucional las facultades subjetivas (right, duty, no-right, power) que implica el derecho en cuestión. En efecto, los autores han utilizado diversas nomenclaturas para explicar esta característica de los enunciados lingüísticos que reconocen derechos fundamentales. Por ejemplo, Zucca la denomina la "generalidad de los derechos"11, Ferreres se refiere a ella como la "ambigüedad y vaguedad de los enunciados" ${ }^{12}$ y Gozzi, en la que parece ser la metáfora más gráfica de todas, prefiere hablar de "incompletezza"13. Cualquiera sea la expresión que se prefiera, todas ellas dejan en evidencia que en dichos enunciados linguísticos existen ciertos datos que la misma norma no proporciona. Esto es crucial a la hora de pensar en garantizar derechos fundamentales, en la medida que estos constituyen un sistema abierto, en la mayoría de la veces no es posible saber con precisión cuáles son todos supuestos regulados y/o la consecuencia jurídica que en cada uno de esos casos procede ante su vulneración. En este sentido, para poder aplicarlos a un caso concreto, se requiere de un ejercicio de determinación o especificación del contenido de los derechos ${ }^{14}$.

\footnotetext{
9 Hohfeld (1916) pp. 710-770.

10 Hesse (2001) pp. 90-91.

11 ZuCCA (2007) p. 7.

12 Ferreres (1997) pp. 19-20.

13 Gozzi (1999) p. 270.

14 Moreso (2005) p. 166.
} 
Frente a este problema una de las soluciones que la dogmática constitucional clásica construyó es la figura de la reserva legal, es decir, es al legislador democrático a quien corresponde realizar dicha labor de especificación constitucional. Esta sería una respuesta satisfactoria y respetuosa del principio democrático, por cierto. No obstante, el constitucionalismo contemporáneo igualmente pone al legislador dentro de la categoría de sospechosos de vulnerar los derechos, por lo que esta respuesta hoy en día solo puede considerarse parcialmente correcta, pues en el modelo casi ortodoxo de constitucionalismo contemporáneo, la última palabra corresponde al juez constitucional, que es quien debe enjuiciar la actividad del legislador. Es aquí donde entran en juego las garantías objetivas.

\section{LA GARANTÍA OBJETIVA DE LOS DERECHOS FUNDAMENTALES}

La garantía objetiva deriva de la especial posición de jerarquía de los derechos fundamentales respecto del resto de las normas del ordenamiento jurídico. La importancia de esta situación es destacada por Modugno" ${ }^{15}$, quien señala que "el solo reconocimiento de los derechos fundamentales en el contexto de una Constitución normativa y garantizada es la primera y más inmediata de las garantías. La garantía objetiva surge como respuesta a una necesidad: abarcar determinados ámbitos de protección que la garantía subjetiva no cubre, en especial, con ocasión de la actividad regulativa que realiza el legislador. Como bien señalan Pérez y Revenga: “[e]l punto de vista del derecho fundamental como interés individual jurídicamente protegido -que es el de la vieja teoría del derecho subjetivo- no permite captar la dimensión de los derechos como elementos que cualifican y otorgan un determinado sesgo al sistema político"16.

Lo anterior quiere decir, nada más y nada menos, que los derechos fundamentales por tener la categoría de normas constitucionales se benefician de las mismas ventajas que el resto del texto de la norma fundamental, concretamente de los principios de supremacía y rigidez constitucional. Por tanto, el legislador cuando realice la función de desarrollar los derechos, podrá delimitarlos pero no limitarlos. Desde luego, que para que un mecanismo de estas características resulte, debe existir un presupuesto lógico (y ontológico): los derechos deben existir objetivamente. Todo esto suena tautológico, pero luego veremos que esta es una cuestión bastante más abstrusa de lo que parece. Pero antes hagamos un poco de historia, ello nos permitirá entender el origen de esta institución.

$\mathrm{Al}$ respecto, no cabe ninguna duda que la teoría de la garantía objetiva como hoy la conocemos, adquiere su partida de nacimiento en el célebre caso Lüth ${ }^{17}$. La relevancia de dicha sentencia es tal, que Casper la ha calificado como "la sentencia más importante en la historia del Tribunal Constitucional Alemán"18. La idea básica que esta expresa es, que si bien los derechos fundamentales son primariamente derechos del ciudadano frente al Estado, encarnan también un sistema objetivo de valores, que se tomará como base constitucional para la determinación de todos los ámbitos del Derecho. Desde esta perspectiva,

\footnotetext{
15 Modugno (2009) p. 87.

16 Pérez y Revenga (2005) p. 19.

17 BVerfGE 7, 198 (205).

18 Casper (2001).
} 
ninguna disposición de Derecho común puede contradecirlos, debiendo ser interpretados de acuerdo con este espíritu.

En las Constituciones europeas de la posguerra estas ideas fueron recepcionadas masivamente, pero también de manera acrítica. En realidad, el problema de la garantía objetiva de los derechos fundamentales había sido uno de los grandes debates en Alemania en la época de la Constitución de Weimar, con las consecuencias ya sabidas por todos ${ }^{19}$. Es que en efecto, garantizar algo que se llame "orden valorativo objetivo" no es una tarea para nada fácil. El principal crítico del constitucionalismo liberal de la época, Carl Schmitt, hace presente esta circunstancia como un verdadero punto débil de la Constitución de Weimar, la que expresaba que los derechos fundamentales son absolutos, pero que al mismo tiempo para dotar de contenido a dichos derechos, en gran cantidad de ocasiones se termina invocando al legislador, por lo que muchas veces "su contenido y límites resultan de las leyes" 20 .

Para establecer una barrera efectiva frente a las amenazas del legislador (y no nos olvidemos, también para que funcionen como derechos subjetivos), se requiere entonces que los derechos puedan dar pie a una decisión racional a la hora de determinar su contenido específico, pues de lo contrario lo único que se produce es un mero desplazamiento desde el legislador a los jueces, respecto de quién tiene la competencia para adoptar decisiones con contenido político, las que en una sociedad democrática desde luego deben ser adoptadas por el cuerpo político y no por funcionarios que carecen de la debida legitimidad popular. En otras palabras, quien defienda la idea de una especificación objetiva de la Constitución como algo verdaderamente objetivo (aquí valga la redundancia), debe estar en condición de responder los múltiples interrogantes que ello plantea, por ejemplo: qué es aquello que las Constituciones denominan contenido esencial, con qué fundamentos hacemos decir cosas a la Constitución en cuestiones donde esta guarda silencio o incluso donde se encuentra el fundamento último de la decisión judicial que entra a resolver cuáles son los principios más valiosos en base a los cuales se asienta la convivencia social.

\section{HÉRCULES LANZANDO UNA MONEDA AL AIRE: ¿PUEDEN LOS DERECHOS FUNDAMENTALES ESCAPAR DE LA DISCRECIÓN JUDICIAL?}

Entonces, la cuestión que nos ocupa la podríamos reformular en los siguientes términos: ¡es posible garantizar los derechos fundamentales teniendo en cuenta su brutal falta de determinación normativa, sin caer en el mero decisionismo judicial? Si la respuesta es sí, entonces la especificación constitucional será una cuestión más bien técnica y el problema se solucionará entrenando a los jueces para que sean más eficaces descubriendo los contornos de aquellas esencias ideales que denominamos derechos. Si la respuesta es no, habría que repensarse seriamente la idea de las Constituciones normativas y garantizadas. La razón ya la sabemos: su indudable costo democrático.

La verdad es que la preocupación por la discreción judicial ha sido desde siempre uno de los debates ineludibles para la ciencia jurídica. Al respecto, en la filosofía del De-

\footnotetext{
19 BÖCKENFÖRDE (2008) pp. 419-421.

20 SchmitT (1982) p. 72.
} 
recho las dos respuestas más famosas a esta pregunta se encarnan en las teorías de Hart y Dworkin. La primera de ellas renuncia directamente a la certeza absoluta, al afirmar que invariablemente existe una suerte de "zona de penumbra" en la que el juez es soberano para crear la regla de Derecho que resuelve el caso concreto, la que obtiene en base a criterios extrajurídicos ${ }^{21}$; la segunda descansa en la idea de que el Derecho nunca puede ser indeterminado y que siempre existe una única respuesta correcta. Al respecto es bastante conocida la metáfora dworkiniana del juez Hércules ${ }^{22}$. Si la tesis de Dworkin es verdadera, no hay ningún peligro en dejar en manos de los jueces cuestiones que inciden de manera directa en nuestra vida cotidiana.

En materia de derechos fundamentales, la versión de esta última teoría que ha gozado de mayor reconocimiento es la de Robert Alexy. La idea central sobre la que descansa, es que los derechos fundamentales son normas que poseen la estructura de principios. Esto significa que a la hora de aplicarlos siempre se debe buscar el mayor grado de realización que permitan las circunstancias fácticas y jurídicas que rodean el caso concreto ${ }^{23}$. No viene al caso aquí analizar en detalle la teoría de Alexy. Lo que es sumamente relevante para nuestro estudio, es que la circunstancia de que los derechos fundamentales sean principios, implica para él una conexión necesaria entre estos y la ponderación como mecanismo racional de aplicación, lo que por ende, justificaría la tesis de la racionalidad de la respuesta judicial. Trataremos de explicar brevemente la defensa que el autor alemán realiza de su teoría, entendiendo que estas ideas son ya conocidas por todos.

La pretensión central de Alexy es que la aplicación del principio de proporcionalidad en el razonamiento judicial asegura la racionalidad en la respuesta del juez frente al desafío de especificar los derechos. Este principio se sintetiza en el siguiente enunciado: "Cuanto mayor es el grado de la no satisfacción o de afectación de un principio, tanto mayor tiene que ser la importancia de la satisfacción del otro" ${ }^{24}$. De acuerdo con esto, en la ponderación que realiza el juez, la medida permitida de no satisfacción o de afectación de uno de los principios depende del grado de importancia de la satisfacción del otro. Ello, según Alexy, pone de manifiesto que el peso de los principios no es determinable en sí mismo o absolutamente, sino que siempre puede hablarse tan solo de pesos relativos. Son solo las circunstancias del caso concreto, las que determinan la dirección en la que deben moverse los principios y también el peso relativo que adquieren en la especie. Por esta razón, para Alexy, el resultado de la ponderación es un enunciado de preferencia condicionada, que se expresa en la siguiente fórmula: (P1 P P2) $\mathrm{C}^{25}$. Respecto, a la operación de construir los enunciados que operarán como premisas sobre las cuales el juez realizará la ponderación, y en definitiva, para determinar el peso específico que adquiere en caso concreto cada uno de

21 HaRT (1963) p. 115.

22 Dworkin (2009) p. 177

23 Alexy (2007) pp. 63-84.

24 Alexy (2007) p. 75.

25 Donde P1 es un derecho cualquiera, por ejemplo la libertad de expresión, P2 otro derecho cualquiera, por ejemplo, el derecho al honor, $\mathrm{C}$ representa las condiciones bajo las cuales un principio se impone al otro y $\mathrm{P}$ expresa la relación de preferencia. 
las circunstancias de la especie, Alexy se remite a los argumentos propios del razonamiento moral y en particular a la teoría de los valores.

Estas ideas han suscitado una verdadera revolución en el Derecho constitucional, no solo por el enorme número de autores que las suscriben, sino porque también han sido recogidas por la jurisprudencia constitucional en Europa continental y en Latinoamérica con bastante frecuencia. En términos simples, todos ellos creen que la solución al problema de la indeterminación existe, que el arbitrio judicial no es tal y que para olvidarnos de él solo basta con entrenar a nuestros jueces en la técnica de la ponderación.

No es este el lugar para repasar todo el debate que ha generado la obra de Alexy. Solo nos remitiremos a las críticas que formula Habermas ${ }^{26}$ pues son las que resultan más atingentes para nuestro trabajo. Dicho autor objeta la vinculación entre derechos fundamentales y razonamiento moral que plantea Alexy, fundándose en la afirmación de que los derechos no pueden ser asimilados a valores. La razón se funda en que ambas nociones operan en planos distintos, los primeros en el plano deontológico, los segundos en el teleológico. Esto tiene importantes consecuencias, porque "las normas (es decir, los derechos fundamentales en su calidad de normas) obligan a sus destinatarios sin excepción y por igual a practicar un comportamiento que cumple con expectativas generalizadas de comportamiento, mientras que los valores hay que entenderlos como preferencias intersubjetivamente compartidas" 27 . De otro modo, los valores fijan relaciones de preferencias, y por lo tanto es posible que un argumento de tipo axiológico consienta grados, pero los derechos fundamentales en tanto normas jurídicas, no son susceptibles de ser cumplidas en la medida de lo posible, sino que como todas ellas, son pretensiones binarias de validez, respecto de las cuales solo podemos tomar postura con un sí o un no (y no con un sí, en la medida de lo posible).

En este sentido, no es posible justificar la utilización de valores dentro de la lógica del Estado de Derecho, pues si jugamos el juego de que los derechos fundamentales son valores, tenemos que aceptar que su utilidad depende de que con ellos se satisfagan ciertos fines, y como los argumentos relativos a fines expresan simplemente preferencias, ellos no son susceptibles de un control racional en el sentido que propone Alexy, pues su pertinencia y peso específico en el caso concreto depende simplemente de quién realice la ponderación.

Expresada en nuestras palabras, la crítica apunta a que, incluso si se pudiera construir una magnitud que midiera los grados de afectación y satisfacción de los derechos fundamentales (cosa que también es bastante discutible), nunca cabría esperar resultados seguros de la ponderación, pues igualmente siguen quedando al arbitrio del intérprete dos cuestiones básicas que terminarán por incidir en el resultado: el contenido de lo que se pondera, (la cuestión de si el derecho a la vida puede o no renunciarse, por ejemplo) y la del peso específico de cada principio en lid. Esto último lo explica muy bien Möeller ${ }^{28}$ cuando señala que, un socialista y un liberal seguramente disentirán profundamente sobre qué peso específico conceden al derecho a la igualdad (en un conflicto entre este derecho

\footnotetext{
26 Habermas (2001) p. 327.

27 Habermas (2001) p. 128.

28 Moeller (2007) p. 463.
} 
y la libertad de expresión o entre este y el derecho a la intimidad). Ello sucede, según este autor, porque el modelo de Alexy tiene una pretensión de neutralidad que busca funcionar con cualquier teoría sustantiva acerca de los derechos fundamentales, pero olvida que cada una de estas versiones produce resultados bastante disímiles en el producto final.

Alexy se defiende frente a la crítica habermasiana de la siguiente manera: "[s]i la tesis de que la ponderación carece de 'medidas racionales' se interpreta literalmente, debe llegarse a la conclusión de que mediante la ponderación no puede establecerse un resultado de forma racional en ningún caso. A esta tesis pueden oponerse dos tesis contrarias, una radical y una moderada. La tesis radical señala que la ponderación establece un resultado de forma racional para todos los casos. La teoría de los principios no ha defendido nunca esta tesis, y por el contrario, siempre ha enfatizado que la ponderación no es un procedimiento que en cada caso conduzca necesariamente a un único resultado. Con ello, todo confluye a la tesis moderada. Esta tesis sostiene que, con ayuda de la ponderación, ciertamente no en todos, pero sí en algunos casos, puede establecerse un resultado de manera racional y que la clase de estos casos es suficientemente interesante como para la existencia de la ponderación como método esté justificada" 29 .

Frente a esta afirmación, lo que uno podría legítimamente contrapreguntar a Alexy es lo siguiente: ¿qué es lo que hay que entender por "casos realmente interesantes”? y ¿cuál es la proporción de casos fáciles (que no necesitan de la ponderación, pues su solución es evidente) versus los casos interesantes? Alexy solamente responde la primera pregunta. Lo hace mediante un ejemplo, en realidad dos: el primero un caso fácil ${ }^{30}$ y el segundo un caso, a su juicio "interesante". El problema es que el segundo ejemplo no hace sino complicar aún más las cosas, y a nuestro juicio, termina dando la razón a Habermas: el asunto trata sobre la condena a una revista de sátira política llamada Titanic, que en diversos números profiere diversas expresiones a un ex oficial del ejército alemán llamándolo "asesino nato" y "tullido". El asunto llega al Tribunal Constitucional Federal vía amparo, el que resuelve que la primera calificación no es tan grave, teniendo en cuenta el carácter irónico de la publicación, y por lo tanto el derecho a la libertad de expresión de la revista debe prevalecer, no así en el segundo caso, donde el adjetivo "tullido" debe ser considerado de todos modos una falta de respeto y una "afectación muy grave" del derecho al honor, con lo que se entra en un ámbito en el que la afectación casi nunca puede justificarse en virtud de la satisfacción de otro interés constitucionalmente protegido ${ }^{31}$.

La verdad es que nos parece que el ejemplo no aclara para nada por qué el Tribunal Constitucional alemán adopta una decisión racionalmente justificada a una de las expresiones de marras más lesiva que la otra. En efecto, no sería extraño que muchas personas pudieran considerar bastante más grave que los tildaran de "asesinos natos" que de "tullidos", y nos parece que nadie podría señalar que dichas personas son irracionales. En definitiva,

29 Alexy (2007) p. 530.

30 El caso fácil es el de las limitaciones que se pueden imponer en cualquier país en virtud de la legislación antitabaco.

31 Alexy (2007) pp. 34 y ss. 
pareciera que el ejemplo no hace sino reforzar la idea de que el intérprete en el método de la ponderación tiene una importancia decisiva en el resultado.

De todos modos, de la defensa que formula Alexy de su tesis, llama la atención la distinción que utiliza entre casos fáciles e interesantes. A nuestro entender, esta no es muy distinta de la clásica distinción hartiana entre casos paradigmáticos y casos difíciles. En este sentido, si interpretamos esa distinción como lo hace Hart, es más sincero reconocer que en estos casos el papel del juez es crear la regla de Derecho que resolverá en definitiva el asunto. Lo anterior no significa que haya que prescindir completamente de la cláusula del contenido esencial ni de la ponderación, sino que simplemente habría que asignarles un rol más modesto, es decir, como conceptos que sirven para justificar una respuesta plausible, pero no necesariamente la única.

En suma, la teoría de la ponderación no resuelve el problema en cuestión, por tanto, salvo que exista otra teoría que desconozcamos, parece que es más realista entender la labor del juez constitucional como esencialmente creadora de Derecho. Ante esta situación, la labor del juez constitucional a la hora de establecer el contenido de las cláusulas indeterminadas en materia de derechos fundamentales, dada la importancia del argumento contramayoritario, debe hacerlo con especial deferencia hacia ciudadanía y el debate político, y para conseguir este resultado, el adecuado diseño de la garantía jurisdiccional es clave. La idea en teoría es sencilla, si a la hora de especificar derechos fundamentales, lo único que nos queda son preferencias u opciones políticas, lo más sensato es que esas preferencias puedan ser construidas participativamente a través de los tribunales, y que además, el proceso de articulación posea ciertas características que aseguren que el debate se plantee como una cuestión de razón pública. Ello nos pone en la necesidad de explorar las opciones de diseño institucional que permitirían implementar estas ideas, pero antes es necesario volver sobre el argumento contramayoritario, para explorar si este deja algún margen para la existencia de un modelo como el que proponemos.

\section{LA JUSTICIA CONSTITUCIONAL COMO COGESTORA DE NUESTROS DESACUERDOS}

Ha sido Jeremy Waldrom el autor que ha planteado las críticas más feroces a la justicia constitucional. El argumento, que espero poder sintetizar adecuadamente, plantea que como los derechos fundamentales nos terminan remitiendo siempre a cuestiones de naturaleza moral, y respecto de estas en nuestras sociedades contemporáneas reina el más profundo desacuerdo, no es correcto si es que nos importa la democracia que estos desacuerdos terminen siendo resueltos por jueces que carecen de legitimación popular, pues en muchas de estas cuestiones (aborto, eutanasia, matrimonio homosexual, solo por poner algunos ejemplos) lo que está en juego son las distintas concepciones morales a las que adhieren los ciudadanos ${ }^{32}$.

En consecuencia, el juez quien tampoco puede sustraerse a su condición de agente moral, en realidad termina resolviendo el problema de acuerdo a sus propias convicciones

32 Waldrom (2005) pp. 107-140. 
personales, bajo la apariencia de hacerlo de manera neutra a través de la aplicación de una regla jurídica. El más claro ejemplo de que estos desacuerdos son tan radicales es que la mayoría de las veces en el Tribunal Supremo de los EE.UU. (que es el locus de referencia en el que sitúa su reflexión) los jueces resuelven sus diferencias votando entre ellos. En este contexto, resulta más legítima la aplicación del procedimiento democrático, pues al menos considera la opinión de cada uno de los ciudadanos y no la de nueve jueces que no responden ante nadie. De esta manera, el procedimiento democrático goza de una dignidad de la que carece la institución de la judicial review para resolver nuestros desacuerdos.

La verdad es que a primera vista la crítica resulta demoledora. No hay que ir muy lejos para darnos cuenta el nivel de resistencia que provocó en nuestro país una sentencia como la rol 740-2008 del Tribunal Constitucional y cómo la teoría de Waldrom nos resulta muy empática cuando este (o la Corte Suprema, según el caso) se arroga poderes de vidente, y sobre todo cuando adopta posturas que no compartimos. Mayoritariamente se ha entendido que la crítica de Waldrom está dirigida al control judicial de constitucionalidad de las leyes, pero si leemos su trabajo con cuidado, aceptar todas sus conclusiones nos lleva necesariamente a prescindir no solo los derechos fundamentales, sino también incluso del concepto mismo de Constitución ${ }^{33}$. En consecuencia, si creemos que aquello que denominamos Derecho constitucional contribuye en algo a que podamos tener una sociedad más libre e instituciones políticas un poco más respetuosas de la persona, deberíamos al menos decir algo contra dicho argumento tan perspicaz.

La respuesta más frecuente que se suele esgrimir frente a la concepción de los desacuerdos de Waldron, es la idea del "consenso por superposición" (Overlapping Consensus) que Rawls plantea en su obra "El Liberalismo Político" ${ }^{34}$. En efecto, esta ha sido usada por diversos autores para fundar interpretaciones sobre derechos tanto en el plano del Derecho interno ${ }^{35}$, como también para justificar alguna teoría de la universalidad de los derechos humanos en el plano internacional ${ }^{36}$. Nosotros no compartimos esta solución, creemos que es una mala respuesta, al menos para responder al dilema que plantea Waldron, pues en realidad, la idea del consenso por superposición está dirigida a resolver el dilema sobre cómo una sociedad liberal, que proclame el valor de la tolerancia como uno de sus principios constitutivos, es capaz de garantizar una estabilidad social en el tiempo. La respuesta que dio el mismo Rawls al problema antes descrito pronto alcanzaría celebridad: resulta que en una sociedad liberal será natural que se produzcan desacuerdos de tipo moral, pues en ella conviven una serie de "doctrinas comprehensivas" ${ }^{37}$ que muchas veces son incompatibles entre sí, no obstante en una sociedad liberal "bien ordenada" ${ }^{8}$ en base a una "razón

\footnotetext{
33 BAYÓN (2010) pp. 285-291.

34 RAWls (1996) pp. 65-70

35 McClain (1998) pp. 1241-1252.

36 Donnelly (2007) pp. 281-306.

37 La expresión comprehansive doctrine, usada por Rawls ha sido traducida así tal cual en la edición en castellano. Se refiere a una concepción moral general acerca de lo que es valioso para la vida humana.

38 Este concepto en la teoría de Rawls expresa aquel orden social, en el que todos sus miembros comparten unos principios básicos de justicia, y en los hechos estos principios informan de manera efectiva las instituciones sociales.
} 
pública" ${ }^{39}$, necesariamente se debe producir acuerdo en relación a unos principios básicos de justicia sobre los cuales se asentarán las instituciones políticas (o más bien lo que Rawls llama la "estructura básica").

Para entender la idea del consenso por superposición, hay que señalar en primer lugar, que este se diferencia de lo que él denomina consenso como modus vivendi, en el que la gente no muestra una adhesión sincera a las instituciones en cuanto tales, sino que acepta acatar sus dictámenes como un mal menor, por ejemplo para evitar la situación de guerra constante que existía en la figura del estado de naturaleza que describía Hobbes.

Ahora mismo, recordemos que la principal objeción de Waldrom es la imposibilidad del consenso en materia de derechos. Con este objeto ataca con todas sus fuerzas la modalidad rawlsiana del consenso. La razón parece ser únicamente el enorme prestigio de que esta última goza, y finalmente, logra dar con su punto débil: la idea de razón pública. Este concepto es clave en Rawls, pues es la manera de construir el consenso entrecruzado en base a las doctrinas comprensivas "razonables". La verdad es que este es uno de los pasajes más obscuros del Liberalismo Político, pues no obstante el mismo Rawls lo niega, da la impresión de que los principios de razón pública allí propuestos coinciden con las condiciones que antes había formulado para su famosa metáfora de la posición original. Allí justamente radica lo controversial, pues el problema parece ser que las reglas de la razón pública, no son sino las que dicta una de las tantas doctrinas comprehensivas en competencia: la justicia como imparcialidad ${ }^{40}$.

La crítica de suyo es razonable. Rawls presenta inicialmente al liberalismo como una de las tantas doctrinas comprehensivas, pero pronto se le olvida y da la sensación de que finalmente esta triunfa sobre todas las otras: "Aun si el liberalismo busca un suelo común y es neutral de propósitos, vale la pena destacar que ello no le impide afirmar la superioridad de determinadas formas del carácter moral", y luego, "los principios de cualquier concepción política razonable deben imponer restricciones a las doctrinas comprehensivas permisibles". Si esto es lo que parece, es decir una afirmación de que existen doctrinas comprehensivas superiores a otras, pero sin explicar el porqué, no cabe duda que Waldrom gana la disputa. El consenso por superposición no es neutro como pretende ser, y por lo tanto un juez lleve estas ideas a tribunales actúa políticamente, al igual como lo haría quien abrazara en su sentencia una defensa del marxismo o del liberalismo libertario.

Sin embargo, para nosotros lo que verdaderamente importa es si la crítica de Waldron puede derribar cualquier posibilidad de consenso. Compartimos su opinión de que el modelo rawlsiano no pasa el test de la imparcialidad. Pero bien, ¿y si la alternativa al desacuerdo radical fuera un modelo más débil de consenso? Recordemos que el mismo Rawls había rechazado la idea del consenso como modus vivendi. La razón creemos, se debe a que no le sirve para justificar su teoría en la medida de que un acuerdo de estas características puede dar perfectamente lugar a un orden no liberal. Con este propósito, presenta la peor versión de esta teoría: la hobbesiana. Ya hemos visto que Rawls parece tener demasiado in-

\footnotetext{
39 El concepto de razón pública es uno de los más obscuros y a nuestro juicio representa una debilidad manifiesta de la teoría del overlapping consensus. Más adelante volveremos sobre ello.

40 Waldrom (2005) pp. 182-194.
} 
terés en que esos principios mínimos sean justamente los liberales, y en concreto los de la teoría de la justicia. En términos empíricos, el hecho de que tal obra haya dado paso a uno de los debates más prolíficos de la historia de la filosofía política refleja que dichos principios no son nada pacíficos y en consecuencia no tienen el mérito que muchos autores les atribuyen.

Afirmar que el consenso por superposición no es la mejor manera de un mínimo común en materia de derechos fundamentales es una cosa. Otra muy distinta es negarse a cualquier tipo de consenso. En este sentido, la teoría de Waldrom es poco realista porque no consigue lidiar con el hecho de que muchas veces en la vida cotidiana logramos ponernos de acuerdo e incluso cooperar con personas que sustentan posiciones radicalmente distintas a las nuestras. En efecto, una sociedad donde reinara el completo desacuerdo apenas podría sostenerse, y seguramente, terminaría fracturada. Es cierto que en determinados ámbitos sería imposible llegar a ningún acuerdo racional entre ciudadanos. Sin embargo, ello no es óbice para que en otros sí podamos comprometernos, aunque sea en un nivel más o menos superficial. Es que en efecto, el mismo procedimiento democrático es un consenso sobre una determinada práctica que funciona en base a unos principios concretos. En un mundo sin consensos básicos ni siquiera la democracia es posible.

A nuestro juicio, es posible encontrar una versión del consenso que satisface de mejor manera el objetivo de describir las prácticas constitucionales existentes en los países occidentales que el desacuerdo radical de Waldrom. Ella es a nuestro juicio una modalidad del consenso como modus vivendi, pero desde luego mucho más realista (optimista dirían algunos) que la que describe Rawls. Una buena descripción, parece ser el modelo de Kurt Baier, que él mismo denomina "consenso constitucional" ${ }^{41}$. De lo que aquí se trata es construir un modelo lo suficientemente valioso para sustituir de modo permamente el uso de la fuerza, aunque ello signifique quedarnos con unos pocos principios de justicia. La lógica del consenso que propone Baier es simple: supongamos que usted y yo necesitamos solucionar una disputa y ya sabemos que no podemos alcanzar una solución consensuada de manera racional. Tenemos aún un par de alternativas: golpearnos o bien lanzar una moneda al aire. Ninguna de estas dos alternativas ha sido considerada en nuestras democracias constitucionales, y seguramente como individuos tampoco estaríamos dispuestos a suscribirlas: la primera, porque puede que mi contrincante sea campeón mundial de boxeo, y la segunda, sencillamente porque la suerte nunca ha sido un aliado en mi vida. Precisamente porque ninguna de estas dos alternativas la consideramos sensatas, las sociedades occidentales han preferido resolver sus diferencias de la siguiente manera: optamos por tolerar al menos algunos pocos principios de justicia, tal vez los mínimos para evitar la violencia directa o indirecta. Sin embargo, sabemos que estos principios en detalle nos pueden llevar a consecuencias inesperadas, donde volverá a reinar el desacuerdo. Es por ello que la decisión del detalle la dejamos a un tercero imparcial. Somos conscientes que este método no siempre nos proporciona la solución que creemos más justa, pero la experiencia indica que es más razonable que la moneda, un golpe en la cara, o incluso la condena en la guillotina por aclamación pública.

${ }^{41}$ BAIER (1989) p. 775. 
En este acuerdo, "parcialmente teorizado" como lo llamaría Sunstein ${ }^{42}$, hay consensos sobre el procedimiento, pero también sobre cuestiones sustantivas. Esto se explica por la especial finalidad que persigue un acuerdo de estas características: permitir de modo definitivo dejar atrás la violencia. Ello no es baladí y determina de manera evidente sus contenidos. Una buena analogía para ilustrar esta figura son las reglas del fútbol. En el fútbol existen reglas sobre el procedimiento (p.e. los jugadores no pueden anotar en posición de adelanto), pero también reglas sustantivas (no se puede golpear o insultar a un rival) la razón es simple, un acuerdo entre 22 personas para jugar al fútbol requiere estos dos elementos, porque si solo existieran reglas procesales, bastaría que un equipo se dedicara a golpear al otro para disminuir considerablemente sus posibilidades de obtener la victoria.

Pasa lo mismo en la democracia. Por ello el consenso constitucional se parece a las reglas del fútbol (o de cualquier deporte de contacto). En primer lugar, contiene un procedimiento para adoptar decisiones de manera pacífica e igualitaria en una sociedad, es decir la regla de la mayoría. Pero en segundo lugar, la misma democracia requiere de ciertas condiciones que permitan asegurar la posibilidad de que los ciudadanos participen en la decisión del cuerpo político, aunque dichas condiciones no siempre resulten del todo claras a primera vista.

$\mathrm{Al}$ respeto, una teoría bastante conocida que conecta esta condición de la democracia con los derechos fundamentales es la de Ely. Dicho autor, justamente, recurre a la metáfora de los tribunales como árbitros que tienen la misión de vigilar el proceso democrático para justificar su existencia ${ }^{43}$. Para él, la justicia constitucional solamente podría actuar legítimamente anulando una ley cuando: "1) quienes detentan el poder bloquean los canales de cambio político o se aseguran de permanecer en el poder y excluir a los demás, o, 2) cuando aunque a nadie se niegue en realidad voz y voto, los representantes comprometidos con una mayoría efectiva sistemáticamente colocan en desventaja a alguna minoría, o por negarse prejuiciadamente a reconocer una comunidad de intereses" ${ }^{44}$.

En definitiva, para Ely, están justificados todos aquellos derechos que son precondiciones del procedimiento democrático (libertad de expresión, asociación, sufragio, etc.). Por el contrario, rechaza la tutela de derechos fundamentales con un contenido sustanti$\mathrm{vo}^{45}$. Él cree, tal como Waldrom respecto de todos los derechos, que en este caso no existe tal cosa como una moral convencional. Por ello creo que se le puede responder de la misma manera que al autor neozelandés: tiene razón si lo que pretende es un detallado corpus sobre los principios de justicia que los tribunales utilizarán para enjuiciar la actuación de los órganos del Estado. Como ya hemos visto, no es verdad que no puedan existir en nuestras sociedades algunos consensos básicos en los términos anteriormente descritos. En efecto, Ely no niega esta posibilidad, lo que pasa es que para él estos carecen de utilidad y es más bien fútil el esfuerzo por aquellos por construir un elenco de valores neutrales y generales.

\footnotetext{
42 SunSTEIN (2009) p. 73.

43 ELY (1997) pp. 97-130.

44 ELY (1997) p. 130.

45 Ely (1997) pp. 85-95.
} 


\section{EL PAPEL DE LOS TRIBUNALES EN UNA DEMOCRACIA}

Tiene razón Ely en que los derechos que se sitúan más allá del mero procedimiento democrático nos complican la vida, no obstante, creemos que esta circunstancia no es decisiva para renunciar a ellos. Si fuera por esto, tampoco deberíamos esmerarnos en proteger aquellos derechos funcionales a la democracia exclusivamente desde el punto de vista del procedimiento. Primero, porque no es tan claro que los derechos que para Ely calificarían en esta última categoría no den origen a problemas interpretativos (considérese el solo ejemplo de la libertad de expresión), pero también porque existe una dificultad adicional. Como señala Gargarella, a Ely uno podría preguntarle legítimamente si no les corresponde también a los tribunales supervisar la aplicación de derechos sociales, con el objeto de impedir el socavamiento de los procedimientos democráticos ${ }^{46}$.

El autor que ha teorizado con mayor éxito acerca de la discreción judicial es H. L. A. Hart. A pesar de que en su obra no se refiere a los derechos fundamentales, lo interesante de su enfoque es que lo hace en el marco de una concepción holística acerca del Derecho, por lo que su análisis debería también servir para nuestro ámbito. Hart ${ }^{47}$ describe el ordenamiento jurídico como una estructura que resulta de la combinación de reglas primarias y reglas secundarias. Según Hart, "las normas primarias se caracterizan por crear derechos e imponer obligaciones"; mientras que las normas secundarias, "por definición, atribuyen poderes". Asimismo, dentro de esta última categoría se distinguen tres tipos de normas secundarias: las reglas de reconocimiento, las reglas de cambio y las reglas de adjudicación. Las dos primeras permiten saber qué normas pertenecen al sistema, la regla de reconocimiento permite determinar cuál es el Derecho originario en un ordenamiento jurídico cualquiera, a su vez, las reglas de cambio indican un procedimiento que permitiría de manera válida modificar el Derecho originario. Las reglas de adjudicación, por el contrario, son aquellas que facultan a determinar autoritativamente si en una ocasión particular se ha transgredido una regla primaria.

Sin embargo, Hart sostiene que este conjunto de distintas clases de reglas que componen el ordenamiento jurídico no siempre proporcionan una solución clara. Es decir, a veces, o porque la regla de reconocimiento o las reglas de cambio se encuentran indeterminadas, el juez debe buscar la solución fuera del ordenamiento jurídico. Como antes hemos visto, este rasgo estructural es sumamente relevante en el caso del Derecho constitucional; pues si existen normas que constituyen un paradigma de indeterminación estas son las que reconocen derechos fundamentales. Para Hart, en los casos en que el Derecho se encuentra indeterminado, no tiene sentido defender que el juez sigue vinculado por la norma, porque justamente allí no hay norma, por tanto, es más realista reconocer que en estos casos es el juez (y no el legislador ni el constituyente) quien crea la regla de Derecho. En consecuencia, según el autor inglés, no estaría prohibido para los jueces fallar de acuerdo a sus propios puntos de vista, "los que pueden ser distintos de los que aplican otros jueces que tienen que decidir casos difíciles similares". Es decir, según esta tesis, habría que concluir

46 Gargarella (2010) p. 423.

47 HaRT (1963) pp. 99-113. 
que en parte importante de los casos difíciles, el juez que aplica la Constitución lo hace siguiendo un método que no puede ser justificado racionalmente

A primera vista, la teoría de Hart puede parecer contraproducente en un modelo institucional como el Estado Constitucional de Derecho, donde justamente, la arbitrariedad se encuentra interdicta. Pero la verdad es que Hart en ningún caso está pensando en un concepto ilimitado de discreción, por el contrario, él señala que se debe hacer la distinción entre discreción y arbitrariedad. Esta distinción es posible debido a que los jueces no tienen el poder de introducir reformas a gran escala como los legisladores, sino que su poder es más bien limitado dado que solo pueden resolver cuestiones concretas planteadas en casos particulares. Por otra parte, los jueces a diferencia del legislador, siempre están limitados por las otras reglas de que sí se encuentran determinadas. Es por ello que señala el autor inglés que a la hora de decidir cuál es la regla de Derecho aplicable al caso concreto, los tribunales "no deben hacerlo arbitrariamente, esto es, siempre deben dar razones generales que justifiquen su decisión y actuar como lo haría un legislador responsable" ${ }^{48}$.

Sin perjuicio de que Hart nunca formuló explícitamente el argumento, justamente, a partir de esta última afirmación es que es posible construir un estándar para valorar la actividad del juez constitucional, y a su vez, construir una regla para delimitar competencias entre este y el legislador. Desde luego, esto no es más que un punto de partida, pues poner este principio en práctica es sumamente complejo, ya que si se quiere seguir hablando en términos hartianos, en el Derecho constitucional la "zona de penumbra" es considerablemente más extensa que en el resto del ordenamiento jurídico.

Por supuesto, nadie diría que la respuesta aquí dada resuelve totalmente el problema del déficit de legitimidad de la jurisdicción constitucional. Pero no hay que olvidar que la principal dificultad del enfoque centrado exclusivamente en el contenido, es que pretende justificar infructuosamente el desplazamiento de poder desde el legislador al juez en virtud de su mejor capacidad para desarrollar la Constitución guardando fidelidad a su texto. Así tal cual hemos planteado las cosas, lo único que hay es un reconocimiento del problema pero no una solución, al menos no una en términos plenos. En efecto, el mismo Hart consciente de ello se consuela afirmando que este es un "bajo precio que hay que pagar" para que el sistema funcione. Nos parece que se puede intentar un argumento de mejor calidad en defensa de la democracia constitucional.

En primer lugar, ese "bajo precio", puede ser más o menos oneroso dependiendo del diseño institucional, y en segundo lugar, hay que agregar que a nosotros nos interesa justamente la opción en que el principio de autonomía de los ciudadanos experimente un sacrificio menor. Sin duda, la razón por la que Hart no desarrolla el argumento en profundidad es porque su trabajo busca ser una teoría meramente descriptiva de lo que es el Derecho. Pues bien, si esto es verdad, a Hart no le deberían importar cuáles son las razones en base a las cuales el juez falla cuando está situado en la "zona de penumbra". Pues a nosotros sí que nos importan; si afirmamos que nuestra propuesta es sensible a la democracia, entonces, no son indiferentes las razones con las que el juez dota de contenido a los derechos fundamentales y enjuicia la ley. Si bien, tal como lo hace Hart, creemos que los tribunales tienen un 
ámbito de discreción para llevar a cabo la especificación constitucional, ello no se debería transformar en discrecionalidad.

De este modo, la metáfora del "legislador responsable" es altamente ilustrativa para entender cómo se debería comportar el juez constitucional al introducir la regla de Derecho al sistema. En efecto, resulta obvio que si aceptamos la idea de que el juez constitucional es un órgano relevante en el proceso de producción normativa, no podemos exigirle menos que a quien tiene la competencia originaria. Si ello es así, entonces la cuestión a responder será precisamente cuáles serán los requisitos de ese actuar "responsable".

En resumidas cuentas, el núcleo de la respuesta centrada en la garantía que sugerimos está dado por la importancia que posee el requisito de la predictibilidad en la construcción de los mecanismos de adopción de decisiones intersubjetivas dentro de la lógica del Estado de Derecho, entre ellas, el contenido y límites de los derechos fundamentales. Como señala Zolo ${ }^{49}$, “[e]l Estado de Derecho se empeña en garantizar a cada uno de los ciudadanos la capacidad de predecir, en línea de principio, consecuencias jurídicas, ya sea de los propios comportamientos o de los comportamientos de los otros actores sociales". En esta misma dirección se expresa Böckenförde ${ }^{50}$, quien sostiene que la noción de Estado de Derecho (y la de Rule of Law para el ámbito anglosajón) parte de la base de que la previsibilidad en la actuación del Estado constituye una garantía para el ciudadano. Desde luego, la ley cumple un papel sumamente importante en este esquema ${ }^{51}$. Es por esta razón, que en el estadio actual desarrollo del sistema de fuentes, no basta con la mera afirmación de que la Constitución es superior jerárquicamente a la ley, sino que además no puede permitirse que la Constitución sea empleada como válvula de escape del núcleo de certeza que aportan las normas infraconstitucionales al ordenamiento jurídico.

Como hemos mostrado anteriormente, la mera apelación al contenido de los derechos fundamentales es insuficiente para afirmar un nivel de previsibilidad necesario que asegure la interdicción de la arbitrariedad. Por esta razón, lo que aquí se propone es que un adecuado diseño de las garantías jurisdiccionales es imprescindible para cumplir este objetivo. Pues bien, ahora que ya sabemos lo que deberíamos exigir al juez a la hora de desarrollar los derechos fundamentales, estamos en condiciones para formular los requisitos concretos de diseño institucional que deberían cumplir sus garantías jurisdiccionales. De esta manera, y para poder cumplir con dicho propósito, estas deberían estar informadas por al menos tres principios: coherencia, universalidad y participación. A continuación explicaremos brevemente qué significan cada uno de estos principios.

En relación a lo primero, si queremos convertir el proceso en un foro deliberativo del contenido de los derechos, la jurisprudencia en la materia no puede ser contradictoria, ni entre distintos tribunales, como tampoco en términos internos. Esta exigencia implica la adopción del principio del stare decisis en alguna de sus modalidades. Como señala Sager, la generalidad con que se expresan la mayoría de las cláusulas que garantizan la libertad exige

\footnotetext{
49 ZOLO (2006) p. 39.

50 BÖCKENFÖRDE (2000) p. 19.

51 LAporta (2007) pp. 127-149.
} 
interpretaciones elaboradas" 52 . Para un juez, los principios por los que se sienta atraído para justificar su decisión en un caso determinado deben ser contrastados en relación a los casos pasados y a los casos futuros ${ }^{53}$. Los jueces están obligados a ofrecer las razones que fundamentan sus decisiones dirigidas, tanto a los demás jueces, como al público en general, y en estas razones deben ser de un tipo especial, a saber: accesibles públicamente y defendibles de la misma manera. Esta es la única forma de posibilitar el debate ciudadano con respecto a esos principios. Esto no quiere decir que la jurisprudencia nunca pueda variar, pero al hacerlo deben existir razones poderosas en tal sentido. A su vez, esta exigencia también impone la necesidad del carácter sistémico de la jurisprudencia en materia de derechos fundamentales, en la medida en que existen distintos tribunales resolviendo sobre lo mismo es importante algún mecanismo de unificación de la jurisprudencia con carácter vinculante. Sobre esto somos conscientes que en el ámbito del civil law no existe una teoría general del precedente, por lo que es normal que una afirmación de estas características siembre muchas dudas y necesita de un mayor desarrollo ${ }^{54}$. No obstante creemos que el esfuerzo vale la pena, es más es indispensable si nos queremos tomar en serio la justicia constitucional. Lo anterior nos permite ligar con el ideal de la universalidad.

La universalidad aquí la debemos entender no en el sentido de objetivismo moral, sino que en sede jurisdiccional, esta hace referencia más bien al ámbito de aplicación de la regla de Derecho creada por el órgano jurisdiccional. En efecto, la jurisprudencia sobre derechos fundamentales debe ser lo menos casuista que se pueda y debe poseer una vocación para producir efectos generales. Si es necesario ser más claro, estamos hablando del efecto erga omnes de las sentencias constitucionales. Sabemos que este requisito se hace imposible en el caso de los mecanismos subjetivos. Por ello se hace necesaria una forma de vinculación entre estos y las garantías objetivas. La razón de esta exigencia está dada por la necesidad de estabilidad y predictibilidad en relación al trabajo que realizan los tribunales desarrollando los derechos.

Por último, los procedimientos de tutela de los derechos deben hacer posible la participación ciudadana. Lógicamente esto tiene poco que ver con la participación electoral. Evidentemente que esta es la modalidad de participación más importante en una democracia, pero ello no quiere decir que sea la única. El mismo Sager explora la idea de cómo el proceso jurisdiccional también es una forma de participación democrática si está diseñado en función de permitir a las partes intervenir realmente y en igualdad de condiciones en la decisión que debe adoptar el órgano jurisdiccional. En efecto, "implícito en esta forma de participación está el derecho a ser oído y obtener una respuesta que sitúe la pretensión e derechos de cada cual dentro del compromiso y la concepción que la comunidad tiene respecto de sus propios miembros" 55 . Esta exigencia se traduciría en términos prácticos en lo inconveniente que resultaría la alteración del principio de bilateralidad de la audiencia y un uso abusivo de procedimientos de cognición limitada o de configuración preferente y

\footnotetext{
52 SAGER (2007) p. 85.

53 SAGER (2007) p. 93.

54 Taruffo (2009) p. 542.

55 Sager (2007) p. 204.
} 
sumaria, sin la posibilidad de llevar la discusión en términos de igualdad de las partes para influir en la decisión del órgano jurisdiccional.

Desde luego, estos principios no son nada más que un medio. Solamente están planteados como condiciones mínimas para concebir a los tribunales como foros de deliberación en materia de derechos fundamentales y por sí solos no son capaces de generar sin una decisión de política judicial. Incluso, algunos de ellos también servirían para implementar una opción política distinta a la que aquí hemos propuesto. Por ejemplo, no cabe duda que la coherencia también sería funcional a un modelo de activismo judicial que no tuviera ninguna consideración por el legislador democrático. No obstante, es la suma de los principios que hemos comentado, unido a las interacciones entre ellos, lo que convierte es diseño acá propuesto el que configura la opción de diseño institucional de la garantía jurisdiccional de los derechos que optimiza en mejor medida dicho objetivo con la democracia

\section{BIBLIOGRAFÍA CITADA}

AleXY, Robert (2007): Teoría de los derechos fundamentales (trad. Carlos Bernal, Madrid, CEPC, segunda edición).

Baier, Kurt (1989): "Justice and the Aims of Political Philosophy", Ethics, núm. 99: pp. 771-790.

BAYÓn, Juan Carlos (2010): “Democracia y derechos: problemas de fundamentación del constitucionalismo", en Carbonell Miguel (coord.), El canon neoconstitucional (Madrid, Trotta) pp. 285-355.

BÖCKENFÖRDE, Ernst (2008): "Cómo se interpretan en el derecho constitucional alemán los derechos fundamentales” en Fernández, Francisco (coord.), Dignidad de la persona, derechos fundamentales, justicia constitucional (Madrid, Dykinson) pp. 415-432.

BöCKENFORde, Ernst (2008): Estudios sobre el Estado de Derecho y la democracia Madrid, Trotta).

Campbell, Tom (2002): La justicia. Los principales debates contemporáneos (trad. Silvina Álvarez, Barcelona, Gedisa).

Casper, Gerhard. (2001): "The 'Karlsruhe Republic - Keynote Addresss at the State Ceremony Celebrating the 50th Anniversary of the Federal Constitutional Court", German Law Journal, vol. 2, núm. 18 [versión electrónica].

Cruz Villalón, Pedro (1989): "Formación y evolución de los derechos fundamentales", Revista Española de Derecho Constitucional, año 9, núm. 25: pp. 35-62.

Donnelly, Jack (2007): “The Relative Universality of Human Rights", en Human Rights Quarterly, vol. 29, núm. 2: pp. 281-306.

DwOrkin, Ronald (1984): Los derechos en serio (trad. Marta Guastavino, Barcelona, Ariel).

Ely, John Hart (1997): Democracia y desconfianza. Una teoría del control constitucional (trad. Magdalena Holguín, Bogotá, Siglo del Hombre Editores).

Fernández Segado, Francisco (1997): "Los sistemas de garantías jurisdiccionales de los derechos”, en VV.AA., Manuel Fraga. Homenaje académico, tomo I (Madrid, Fundación Cánovas del Castillo) pp. 463-532.

FERreres, Víctor (1997): Justicia constitucional y democracia (Madrid, CEPC). 
GARrido, María Isabel (2007): Derechos fundamentales y Estado social y democrático de Derecho (Madrid, Dilex S.L.)

Gargarella, Roberto (2010): "Una disputa imaginaria sobre el control judicial de las leyes. El 'constitucionalismo popular' frente a la teoría de Nino” en Carbonell Miguel (coord.), El canon neoconstitucional (Madrid, Trotta) pp. 403-426.

GozzI, Gustavo (1999): Democrazia e diritti. Germania: dallo stato di diritto alla democrazia costituzionale (Bari, Editori Laterza).

Hart, Herbert (1963): El concepto de Derecho (trad. Genaro Carrió, Buenos Aires, Abeledo Perrot).

Hart, Herbert (1997): "Post Scriptum (El concepto de Derecho)", Estudios Públicos, núm. 65: pp. 223-263.

Habermas, Jurgen (2000): Facticidad y validez. Sobre el derecho y el estado democrático de derecho en términos de teoría del discurso (Madrid, Trotta).

Habermas, Jurgen y Regh William (2001): "Constitutional Democracy: A Paradoxical Union of Contradictory Principles?”, Political Theory, vol. 29, núm. 6: pp. 766-781.

Hesse, Konrad. (2001): "Significado de los derechos fundamentales", en AAVV, Manual de derecho constitucional (Madrid, Marcial Pons) pp. 83-115.

Hohfeld, Wesley (1916-17): "Some Fundamental Conceptions as Applied in Judicial Reasoning”, Yale Law Journal, núm. 29: pp. 710-770.

LAPOrTa, Francisco (2007): El imperio de la ley. Una visión actual (Madrid, Trotta).

López Guerra, Luis (2004): “La garantía de la Constitución”, en Peces-Barba, Gregorio (coord.), La Constitución a examen. Un estudio académico 25 años después (Madrid, Marcial Pons) pp. 237-255.

Mcclain, Linda (1998): "Deliberative Democracy, Overlapping Consensus, and Same-Sex Marriage”, Fordham Law Review, vol 66, núm. 4: pp. 1241-1252.

Moeller, Kai (2007): "Balancing and the structure of constitutional rights", International Journal of Constitutional Law (NYU),vol. 5, No 3: pp. 453-468.

Moreso, José Juan (2005): "Sobre los conflictos entre derechos" en Carbonell, Miguel (coord.), Garantismo. Estudios sobre el pensamiento jurídico de Luigi Ferrajoli (Madrid, Trotta).

Modugno, Franco (2009): Lineamienti di teoria del diritto oggetivo (Turín, Giappichelli Editori).

Pérez Luño, Antonio (2007): Los derechos fundamentales (Madrid, Tecnos, novena edición).

Perry, Michael (2003): "Protecting Human Rights in a Democracy: What Role for the Courts”, Wake Forest Law, núm. 38: pp. 635-696.

Pérez Tremps, Pablo y Revenga, Miguel (2005): "La protección de los derechos fundamentales en España”, en Pajares, Emilio (coord.), La protección de los derechos fundamentales en Brasil, Colombia y España (Valencia, Tirant lo Blanch-Instituto de Derecho Público Comparado Universidad Carlos III) pp. 17-56.

RAWLS, John (2004): El liberalismo político (trad. Antoni Domènech, Barcelona, Crítica).

SAGER, Lawrence (2007): Juez y democracia. Una teoría de la práctica constitucional norteamericana (trads. Víctor Ferreres y Aida Torres, Madrid, Marcial Pons). 
SEN, Amartya (2001): "Rights, Laws and Language", Oxford Journal Legal Studies, vol 31, No 3: pp. 437-453.

Schmitt, Carl (1982): Teoría de la Constitución (Madrid, Alianza).

Sunstein, Cass (2009): A cosa servono le costituzioni (trad. V. Ottonelli, Bolonia, Il Mulino).

Taruffo, Michelle (2009): Páginas sobre justicia civil (Madrid, Marcial Pons).

Waldrom, Jeremy (2005): Derecho y desacuerdos (trads. José Luis Martí y Águeda Quiroga, Madrid, Marcial Pons).

Zolo, Danilo (2006): "Teoria e critica dello Stato di diritto", en Costa, P. y Zolo, D. (coords.), Lo Statto di diritto. Storia, teoria, critica (Milán, Feltrinelli,) pp. 17-88.

Zucca, Lorenzo (2007): Constitutional Dilemmas. Conflicts of Fundamental Rights in Europe and USA (Nueva York, Oxford University Press). 
